\title{
A TEORIA POLÍTICA VISIGODA
}

Maria Sonsoles Guerras Martin*

SINTESE - Os visigodos, que professavam o arianismo desde antes de seu estabelecimento na $\mathrm{Pe}$ ninsula Ibérica, converteram-se ao Catolicismo de Nicéia em fins do século VI, por ocasiäo do III Concílio de Toledo, realizado em 589 . Os vínculos entre a Igreja e o Estado, a partir deste momento, tornaram-se estreitos.

A teoria política que sustentou ideologicamente o Reino Visigodo, deste momento até a chegada dos muçulmanos, encontra-se, fundamentalmente, nas obras de Isidoro de Sevilha e nas Atas dos Concílios de Toledo. Tais documentos serão objeto de nosso estudo, que visa a reconstrução das linhas mestras desta teoria política.
ABSTRACT - The Visigoths, which professed the Arianism since the establishment on the Iberian Peninsula, converted themselves to the Catholicism of Nicaea, on the end of the VI century, when the council of Toledo took place in 589. The links between the Church and the State, became close from this moment on.

The political theory that ideologically supported the Visigoth kingdom, from this moment on until the arrival of the Mussulmans, is found fundamentally in the books of Isidoro de Sevilha and in the records of the councils of Toledo. Such documents will be object of our concern, that aims at the reconstruction of the master lines of this political theory.

Freqüentemente se estuda a teoria política dentro do campo da história das idéias e os elementos políticos são vistos algo assim como corpos passivos que se modificam pelas teorias.

Acompanhando o pensamento de Abilio Barbero de Aguilera, insigne hispanista, especialista em história medieval, trataremos de seguir um caminho diferente explicitando inicialmente o quadro histórico que fez possível o nascimento da dita teoria política visigoda.

\section{I - Os antecedentes}

Os visigodos são um dos povos germanos que invadiram as províncias do Império Romano no século $\mathrm{V}$. Tinham vivido com anterioridade durante muito tempo nas fronteiras participando de um ativo comércio econômico e cultural com os exércitos romanos. Converteram-se ao cristianismo professando a heresia ariana. No século IV, quando ainda estavam nas margens do rio Danúbio, foram o primeiro povo germano que traduziu para a sua língua a Bíblia, obra do bispo Ulfilas.

Universidade Federal do Rio de Janeiro - UFRJ.

\begin{tabular}{|l|l|l|l|l|l|}
\hline VERITAS & Porto Alegre & v. 40 & $\mathrm{n}^{\mathrm{9}} 159$ & Setembro 1995 & p. 369-378 \\
\hline
\end{tabular}


Mais tarde, estabeleceram-se dentro do território imperial, sendo aliados do povo romano e passando a desempenhar papel de grande importância na política imperial.

No início do século $\mathrm{V}$, em 410, invadiram Roma saqueando-a durante três dias, chefiados por Alarico. Sentem-se os reflexos da terrível crise que este fato provocou em todo o mundo romano nas obras de grandes pensadores da época. Citamos, apenas, como exemplo, a Cidade de Deus, de Santo Agostinho e o Epistolário, de São Jerônimo.

O Império, para livrar-se da presença dos visigodos dentro da capital, estabeleceu com eles um pacto de federação e os enviou às partes mais ocidentais do Império: as Gálias e Hispânia, para que, em nome de Roma e para restabelecer a unidade, expulsassem os outros povos germanos: suevos, vândalos e alanos, que tinham ultrapassado o limes romano pouco tempo antes.

Os visigodos, assim, chegam a estabelecer sua capital, em Toulouse durante 90 anos, até que a pugna franco-gótica pela hegemonia das Gálias se resolvesse em um grande enfrentamento militar. A batalha de Vouillé, perto de Poitiers, em 507, obriga os visigodos a abandonar a Gália e a instalar-se definitivamente na Peninsula Ibérica, estabelecendo sua capital em Toledo. A partir deste momento se configura o Reino visigótico espanhol, que está dividido em dois grandes períodos, denominados tradicionalmente de Reino Ariano e Reino Católico. A linha divisória se estabeleceu com a conversão ao catolicismo do rei Recaredo no ano de 589 durante a realização do III Concílio de Toledo.

Embora nosso trabalho faça referência direta ao Reino Católico visigodo é necessário lembrar antes a figura e a obra de Leovigildo, pai de Recaredo, último monarca ariano, considerado como o maior entre todos eles, pelos seus dotes de estadista e de guerreiro.

A primeira tarefa de Leovigildo, quando de sua ascensão ao trono, foi de efetivar a autoridade da monarquia sobre quase todo o território peninsular, anexando também o extremo nor-ocidental onde reinavam os suevos desde o século anterior. ${ }^{1}$ Não somente conteve a desagregação que ameaçava fragmentar a Península em diminutos Estados, submetendo à sua autoridade a maior parte do território e levando a cabo uma importante ação organizadora, como, também, e principalmente, fez um grande esforço no sentido de captar ambas populações - godos, arianos e hispano-romanos, católicos - em torno de sua pessoa: o rei, e de sua religião: a ariana.

A política de Leovigildo foi, pois, uma política centralizadora, de unificação, que pode ser medida, entre outros dados que poderiam ser citados, através de sua obra de reforma de legislação visigoda. O resultado do esforço foi o Codex Revisus, ou seja, a revisão do antigo Código de Eurico. Embora não conservado integralmente, muitas de suas leis nos foram transmitidas através do Forum iudicum. Eliminou, por exemplo, o artigo que concedia preponderância aos godos quando brigavam com um romano em questões de doações e venda de bens.

1 ORLANDIS, José. Historia del Reino visigodo español. Madrid: Rialp, 1988, p. 71. 
Outra lei digna de ser tomada em consideração, também, é a anulação da constituição dos imperadores Valente e Valentiniano que, desde o ano de 370, proibia os matrimônios mixtos entre godos e romanos.

Manifestação tangivel também da afirmação de sua autoridade foi a acunhação de moedas de ouro que, pela primeira vez no ocidente, não levam o nome do imperador romano e sim o dele, o próprio rei Leovigildo. ${ }^{2}$

"Foi o primeiro, diz Isidoro de Sevilha, que se apresentou aos seus súditos em trono e com as vestes reais, pois antes dele os hábitos e os assentos eram iguais para o povo e para os reis". ${ }^{3}$

Leovigildo alterou também a política que havia prevalecido até então baseada na dualidade catolicismo-arianismo. Resolveu promover a unidade de todos os seus súditos do reino Toledano com independência de sua procedência étnica. Reuniu um Concílio de bispos arianos em Toledo, no ano de 580, onde se tomaram os seguintes acordos: $\left.1^{9}\right)$ deveria ser formulada uma doutrina relativa à Sma. Trindade que fizesse concessões aos católicos; $2^{\text {9 }}$ ) facilitar-se-ia a passagem dos católicos à confissão ariana, suprimindo-se algumas exigências que representavam psicologicamente um obstáculo importante; $3^{2}$ ) a política deveria ser, de agora em diante, de atração dos católicos e, caso não surtisse efeito, prevaleceria a ação persecutória com desterros e confiscações; $4^{\circ}$ ) Leovigildo deveria esbanjar gestos externos como sejam: visitas às igrejas católicas e aos sepulcros dos mártires como meio de semear a confusão no povo católico. ${ }^{4}$

Se é verdade indiscutível que a procura da unidade em três campos fundamentais, territorial, jurídico e religioso, inspiraram toda a ação política de Leovigildo, não o é menos que sua política religiosa terminou em um completo fracasso, apesar da afirmação de Gregório de Tours, que se encontra na História dos Francos e diz: "Leovigildo morreu depois de ter renunciado publicamente ao arianismo e ter confessado a fé católica". 5

A morte de Leovigildo assinala o fim de uma etapa da Espanha visigoda. Ele fracassou no desejo de unir godos e romanos, arianos e cristãos, sob uma mesma fé, a ariana, e Recaredo, seu filho, substituindo-a pela fé católica alcançou o resultado desejado. O Estado visigodo consegue assim uma coesão que até então nunca tinha tido. A unidade confessional que se considerava chave para a política realizou-se em torno ao catolicismo pelo novo rei, Recaredo. Ele perseguia os mesmos objetivos do fortalecimento do poder régio de seu pai e preferiu, ao contrário dele, o caminho do acordo com a grande aristocracia eclesiástica e o apoio legitimador do episcopado. O Reino de Toledo alcançou o máximo grau de homogeneidade étnica, cultural, politico-administrativa e até geográfica. ${ }^{6}$

2 idem, p. 77.

3 ISIDORO DE SEVILIA. Las Historias de los godos, vándalos y suevos. Edición de Cristobal Rodriguez Alonso. León: Centro de Estudios S. Isidoro, 1975. p. 254.

4 ORLANDIS, José \& RAMOS-LISSON, Domingo. Historias de los Concilios de la Éspaña Romana y visigoda. Pamplona: Universidad de Navarra, 1986. p. 298.

5 GREGÓRIO DE TOURS. L'histoire des rois francs. Edic. de J. J. E. Roy. Paris: Gallimard, 1968. p. 167.

6 GARCIA-MORENO, Luis A. Historia de España visigoda. Madrid: Cátedra, 1989. p. 111. 
Estes dois reinados de Leovigildo e Recaredo marcam a hora de profundas mudanças no reino visigótico de Toledo.

\section{II - Recaredo e o III Concílio de Toledo}

Recaredo, como falamos anteriormente, professou publicamente a fé católica no III Concílio de Toledo que teve início a 8 de maio de 589, no que foi seguido por bispos e varões ilustres, representantes do povo visigodo. Ao rei se deveu a iniciativa da celebração do Concílio e a proposta dos principais temas a tratar, contidos no "tomo regio". Formularam-se 23 cânones que foram aprovados pela totalidade do episcopado do reino, conforme as Atas conservadas.

Registramos alguns dados relativos a este III Concilio que não podem passar desapercebidos. No "tomo regio" Recaredo afirma que a origem do poder está em Deus ao dizer: "o Deus onipotente nos deu a carga do reino em favor e proveito do povo e encomendou não poucas gentes ao nosso régio cuidado [... $]^{1{ }^{7}}$ e repete mais tarde: "devemos cuidar das gentes que o Senhor nos confiou [...]". 8

Finalizada a leitura do "tomo" o Concílio rompeu em aclamações ao rei a quem deu o titulo de "conquistador de novos povos para a Igreja Católica" ${ }^{9}$ e pèdem a Deus "que mereça o prêmio apostólico porque cumpriu o oficio de apóstolo". ${ }^{10}$

Estas aclamações conciliares lembram as dirigidas aos grandes imperadores cristãos do Oriente. Recaredo é comparado a Constantino, por ter renovado em Toledo a gesta de Constantino, condenando o arianismo no Concilio de Nicéia em 325 , e passa a assinar seu próprio nome com o gentílico da dinastia constantiniana: Flavius Recaredus.

Nos cânones aprovados encontramos a ação dos bispos intervindo na administração civil. Assim, por exemplo: o XVIII ordena que uma vez por ano se reúnam os Concílios Provinciais e estejam neles presentes os juízes e arrecadadores do fisco

"para que aprendam a tratar ao povo piedosa e justamente sem lhes impor prestações ou imposições supérfluas, e, de acordo com o desejo do rei, os bispos deverão inspecionar os juizes em seus próprios lugares de trabalho para que, avisando-os, se corrijam e, caso isto näo aconteça, dêem conta ao rein."

e o XVII aprova que "os juízes investiguem em união com o bispo, muito diligentemente, o crime e os proibam com toda severidade". ${ }^{12}$

Um outro dado a levantar é o fato de os cânones transformarem-se em lei civil mediante a confirmação do rei. O Edito de Recaredo diz assim:

"Mandamos com nossa autoridade a todos os homens, submetidos ao nosso reinado, que a ninguém lhe seja permitido desprezar e que ninguém se atreva a prescindir de tudo quanto foi estabelecido neste santo Concilio [...] que as determinações sejam observadas e se man-

7 CONCLIOS VISIGÓTTCOS E HISPANO-ROMANOS. Edic. de José Vives. Madrid: C. S. I. C. 1963. p. 108.

8 idem, p. 109.

9 idem. p. 112.

10 idem, p. 117.

11 idem, p. 131.

12 idem, p. 130. 
tenham em vigor, tanto para os clérigos, como para os leigos, como para qualquer classe de homens."

$\mathrm{E}$, depois de resumir todas as constituições, conclui assim:

"Se algum clérigo ou leigo não quiser obedecer a estas determinações [...] seja excomungado por todo o Concilio. Se se tratar de um leigo e for de elevada condição, perca a metade de sua fortuna em favor do fisco e se, finalmente, for um homem do povo, que perca todos os seus bens e vá para o exilio. Eu, Flavio Recaredo, assinei em confirmação". ${ }^{13}$

Luis Garcia Moreno, especialista em história dos visigodos, afirma que tudo isto significa o reconhecimento por parte da monarquia visigótica do poder e influência institucional da Igreja e hierarquia eclesiástica, dominada por sua vez pela nobreza hispano-goda e, ao mesmo tempo, que os homens desta época se preocupavam por encontrar um porquê à História no duplo sentido da universalidade da Divina Providência e do Direito público da tradição romana: ${ }^{14}$

Reydellet em seu clássico artigo sobre a concepção do soberano em Isidoro de Sevilha diz que, no início do século VII, encontramos no Reino de Toledo dois fatos de capital importância: a afirmação constante do poder régio em quase toda a extensão da Península Ibérica e a conversão de Recaredo ao catolicismo no III Concílio de Toledo, mas que, o que este Reino não tem ainda, é uma ideologia e as regras fundamentais que lhe darão, mais tarde, suas características essenciais. ${ }^{15}$

\section{III - Isidoro de Sevilha e a teoria politica visigoda}

Isidoro de Sevilha é quem dá forma ao pensamento político visigodo recolhendo duas heranças: a do mundo clássico e a cristã. Para ele o corpo formado pelo conjunto das nações germanas é a Igreja e não mais o Império. A Igreja está formada por esta pluralidade de nações e constitui um grande reino e os principes devem apoiar pela força o que os sacerdotes não podem impor pela palavra. ${ }^{16} \mathrm{Tam}$ bém a realeza Davídica é exemplo a seguir.

No entanto, em Isidoro persiste também a idéia romana do Baixo Império de que o poder procede de Deus, quem o outorga diretamente ao príncipe sem nenhum intermediário. O rei, portanto, é o único mediador entre a divindade e o povo de quem deve prestar contas.

Ele é o único responsável; por isso, só a ele, o rei, corresponde dar as leis e ordenar toda a vida da sociedade sem distinguir entre o temporal e o espiritual, já que, de ambas coisas deve dar conta a Deus. É por isso que os reis intervém, igualmente, nos assuntos civis e nos eclesiásticos, nomeiam bispos, regulam a vida cristã do clero e do povo, participam em disputas teológicas, etc.

Isidoro de Sevilha é uma figura brilhante na Espanha visigoda do século VII. Foi mestre, pedagogo, abade, bispo e político, conhecedor da cultura clássica

13 idem, p. 135-36.

14 GARCIA MORENO. Luis A. op. cit.: p. 112.

15 REYDELLET, Marc. "La conception du souverain chez Isidore". In: ISIDORIANA Estudios sobre Isidoro de Sevilla en el XIV centenario de su nacimiento. León: Centro de Estudios S. Isidoro, 1961. p. 546.

16 BARBERO DE AGUILERA, Abilio. La sociedad visigoda y su entorno histórico. Madrid: Siglo XXI, 1992. p. 20. 
como quase ninguém em sua época e escritor dos mais variados temas: Teologia, Política, Filosofia, História, Direito, etc. A fama que o acompanhou foi tão grande que, alguns séculos depois, Dante, na Divina Comédia, o colocou no Paraíso, ao lado de Santo Agostinho e de Santo Tomás de Aquino.

Os Padres do VIII Concílio de Toledo, reunidos em 653, disseram que "Isidoro, o doutor egrégio do nosso tempo e o mais ilustrado de todos os homens neste século, é digno de ser lembrado com toda reverência". ${ }^{17}$

Jacques Fontaine, o maior especialista na atualidade sobre S. Isidoro, afirma que foi o último sábio da Antiguidade.

Entre as múltiplas e variadas obras escritas por Isidoro, as que nos interessam especialmente hoje, são: As Sentenças, as Etimologias e a História dos Godos.

Os três livros das Sentenças ou Livro do Sumo Bem, título extraído da primeira frase, foram escritos por volta de 615 . São um verdadeiro manual dogmático, moral e ascético. Madoz afirma que a obra contém uma dogmática, uma ética individual e uma ética social. ${ }^{18}$

O primeiro dos livros é uma síntese da fé cristã; o segundo aborda o processo da conversão: os vícios e as virtudes; e o terceiro, dentro do seu perfil ascéticomoral, oferece uma orientação prática com caráter social. Neste terceiro livro encontramos a imagem do príncipe ideal em cinco capítulos: do 47 ao 51 .

Logo no primeiro capitulo citado, $\mathrm{n}^{\circ} 47{ }^{19}$ encontramos duas constantes do pensamento isidoriano: o poder vem diretamente de Deus e foi estabelecido por Ele para o bem comum.

"O justo Deus dispôs a vida dos homens constituindo a uns servos e a outros senhores, a fim de que a licença dos súditos para fazer o mal fosse reprimida com o poder dos soberanos [...] Por isso é que entre os povos todos sempre houve príncipes e reis a fim de reprimir a mal."

Estes mesmos pensamentos se explicitam mais ainda no capitulo 48:20 "É bom o poder recibido de Deus para reprimir o mal [...]" e a seguir comenta a frase do Apóstolo Paulo: "Não há autoridade que não provenha de Deus". ${ }^{21}$

$O$ rei para Isidoro deve sempre exercer o bem:

"Receberam o nome de reis para agir ou reger com retidão. E por isso que conserva o nome de rei se age corretamente e o perde com o pecado e aquele que governar bem temporalmente, reinará sem fim na eternidade" ${ }^{22}$

Isidoro, desejando detalhar mais o retrato do príncipe, dedica os três capitulos seguintes à justiça, à paciência do príncipe e a como eles também estão sujeitos às leis. "Aquele que usa retamente da autoridade real estabelece a justiça com os fatos mais do que com as palavras" afirma no capítulo $49^{23}$ e no 50: "muitas vezes acontece que o príncipe justo dissimula os defeitos dos maus, e isto, não porque

17 CONCIIIOS VISIGÓTICOS E HISPANO-ROMANOS. op. cit.: p. 276.

18 MADOZ, José. San Isidoro de Sevilla. León: Centro de Estudios S. Isidoro, 1960. p. 125.

19 SANTOS PADRES ESPAÑOLES: SAN LEANDRO, FRUCTUOSO e ISIDORO. Obras. Edic. de Julio Campos Ruiz e Ismael Roca Melia. Madrid: BAC, 1971. p. 492.

20 idem, p. 493.

21 Romanos, 13, 1.

22 SANTOS PADRES ESPAÑOLES. op. cit.: p. 494.

23 idem, p. 496. 
consinta na iniqüidade e sim porque espera o tempo propício para a correção" e mais tarde: "quem junta a clemência à justiça não devolve mal por mal aos maus e responde às ofensas com o bem". ${ }^{24}$

No último capitulo intitulado: "os príncipes estão sujeitos às leis", diz que é justo que o rei obedeça à lei para depois afirmar, numa elevação de tom, que "os príncipes estão obrigados a cumprir as leis e não podem revogar, em seu próprio favor, os preceitos que estão estabelecidos para os súditos. ${ }^{125}$

Também faz referência às relações do rei com a Igreja: "os poderes seculares estão submetidos à disciplina religiosa [...] conservam, às vezes, as prerrogativas do poder recebido para proteger, com este mesmo poder, a disciplina eclesiástica". E termina com uma severa advertência em que deixa claro que a proteção da Igreja corresponde aos príncipes seculares e que só a Deus eles terão de prèstar contas. ${ }^{26}$

Uma outra obra de Isidoro onde podemos encontrar de forma teórica seu ideário político, são as Etimologias. Esta é a grande obra de Isidoro, aquela que lhe deu fama e prestígio durante séculos. É uma vastíssima enciclopédia onde se encontram reunidos, sob os lemas de palavras usuais ou pouco freqüentes, todos os campos da sabedoria antiga, explicados pela justificação dos termos com que se designam. É um compêndio de conhecimentos classificados segundo temas gerais. ${ }^{27}$

O capítulo 3 do livro IX nos dá todas as definições de rei, imperador, cônsul, ditador, césar, etc.

Reino, diz, deriva de rei; como os reis tomam seu nome de reger, assim o reino o toma dos reis. $E$, rei deriva de reger, como sacerdote de sacrificar. Não rege aquele que não corrige. $O$ nome de rei se possui quando se age corretamente e perde-se quando se age mal. Daqui o provérbio que diziam os antigos: 'Serás rei se obras com retidăo, e se não obras assim, não o serás'. As virtudes régias são principalmente duas: a justiça e a piedade" ${ }^{28}$

Como podemos apreciar, a doutrina é a mesma que encontramos nas Sentenças. A obrigação fundamental do rei é agir com justiça e propiciar o bem aos súditos. O que não está explicitado nas Etimologias, neste capítulo, é a afirmação da origem do poder que vem de Deus, como vimos nas Sentenças.

Examinadas estas obras em que Isidoro expõe seu pensamento sobre o príncipe, podemos repetir com Reydellet ${ }^{29}$ que "o título de rei constitui para aquele que o leva uma clara vocação à santidade e que o governo é uma empresa de saúde coletiva".

Vejamos agora na História dos godos qual é o retrato que Isidoro faz de alguns reis. É a teoria na prática.

O retrato de Recaredo diz assim:

"Foi pacifico, delicado, de notável bondade. Retratou em seu rosto tão grande benevolência e teve em sua alma tão grande benignidade que influia no ânimo de todos e até conseguia 0 carinho e afeto dos maus. Foi tão liberal que devolveu aos seus legitimos donos os bens dos

24 idem, p. 497-98.

25 idem, p. 499.

26 idem, p. 500.

27 ISIDORO DE SEVIL_A. Etimologias. Edic. de José Oroz Reta. Madrid: BAC, 1982. 2 v. v. 1. p. 163.

28 idem, p. 765.

29 REYDELLET, Marc. op. cit.: p. 461. 
particulares e as propriedades das igrejas que o erro do seu pai tinha entregado ao fisco. Foi tão clemente que muitas vezes exonerou o povo dos tributos devidos [... $]^{33}$

Chama ao rei de "religiosíssimo príncipe" ${ }^{131}$ e diz que "suas guerras foram gloriosas contra os inimigos e conservou com paz e administrou com begnidade e regeu com moderação, os territórios recebidos do pai". ${ }^{2}$

Em Suintila admiramos ao rei que

"tinha muitissimas virtudes próprias da majestade real: fidelidade, prudência, habilidade, exame extremado nos juízos, atenção fundamental ao governo do reino, munificência para com todos, generosidade para com os pobres e necessitados, pronta disposição para o perdão. É por isso que mereceu ser chamado, não só príncipe dos povos, mas também pai dos pobres. $^{\text {H3 }}$

São as palavras de Isidoro e continua ainda:

"O gloriosíssimo Suintila tomou o cetro do poder pela graça de Deus ${ }^{34}$ [...] e conseguiu a glória de um triunfo superior ao dos demais reis, visto que foi o primeiro que conseguiu o poder monárquico sobre toda a Espanha peninsular, fato que não se deu em nenhum outro principe anterior." $^{\text {35 }}$

Até conseguiu vencer aos terriveis povos vascões, que nem sequer foram dominados pelos exércitos de Augusto. Estes "jogaram ao chão as armas, se ajoelharam suplicantes e prometeram obediência ao seu reino e à sua autoridade, jurando cumprir quantas ordens lhes fossem impostas". ${ }^{36}$

Nestas obras citadas encontramos o retrato do príncipe ideal, conforme o pensamento isidoriano, seja na forma teórica, como tratado de Ética, seja na de um relato da vida e virtudes dos reis que conseguiram, ou estiveram muito perto de conseguir, a perfeição almejada.

Resta, para finalizar, ver a Isidoro, já perto dos 80 anos, na maturidade de uma vida muito rica, cumprindo o último e, possivelmente, o mais brilhante momento de sua atuação política, a coroação e consagração definitiva de todos os seus esforços. Foi a preparação, orientação e direção do IV Concílio de Toledo no ano de 633.

O IV Concílio de Toledo foi o primeiro de uma série de concílios de inspiração isidoriana e natureza essencialmente normațiva. É o Concilio que representa a consolidação do Reino Visigodo católico e que reveste extraordinária transcendência, tanto na ordem eclesiástica, como na política. ${ }^{37} \mathrm{O}$ Reino de Toledo encontrava-se frente a um problema concreto que exigia a reafirmação das estruturas políticas. 0 rei Suintila tinha sido deposto pelos nobres que colocaram no trono a Sisenando. Tornara-se imprescindivel, tanto por parte da realeza, como da Igreja e da nobreza, uma normativa que, estabelecendo de uma vez por todas a sistemática da eleição régia, contribuiu-se à consolidação do Reino.

30 ISIDORO DE SEVILLA. Las Histórias... op. cit.: p. 267.

31 idem, p. 263.

32 idem, p. 265.

33 idem, p. 279.

34 idem, p. 277 .

35 idem, p. 272.

36 idem, p. 279.

37 ORLANDIS, José \& RAMOS-LISSON, Domingo. op. cit.: p. 262. 
Este Concílio reuniu a totalidade dos bispos da Peninsula, 69, e aprovou 75 cânones. Foi convocado, como de costume, pelo rei que, igualmente, entregou o "tomo régio", ou seja, a relação dos problemas que deveriam ser tratados.

O último cânone, o 75, começa assim:

"Depois de ter estabelecido algumas coisas referentes à ordem eclesiástica e decretado medidas disciplinares [...], a última decisão de todos nós, bispos, tem sido redigir, na presença de Deus, o último decreto conciliar que fortaleça a situação de nossos reis e dê estabilidade ao povo dos godos." ${ }^{38}$

A estruturação deste cânone não se enquadra na mesma sistemática de todos os outros. Começa explicitando a problemática: "Tem muitas pessoas que desprezam guardar a fidelidade prometida com juramento a seus reis [...] e não temem o juízo de Deus para com aqueles que juram mentirosamente...". Apoia-se na autoridade da Sagrada Escritura e lembra as palavras de David: "quem estenderá a mão contra o ungido do Senhor e será inocente?" para passar, num segundo momento, à exortação:

"Permaneçamos até a morte na fidelidade e promessas que fizemos aos nossos reis [...], que ninguém arrebate 0 trono [...], que ninguém prepare a morte do rei, que ninguém excite as discórdias civis entre os cidadäos".

Depois de toda esta preparação psicológica aparece claramente a fórmula da sucessão régia: "[...] a nobreza do povo, em união com os bispos, designarão, de comum acordo, ao sucessor no trono $[. . .]^{139}$

Escolhe-se, portanto, o sistema de eleição, e esta deverá ser feita pela nobreza em união com os bispos. Fica claramente expressada a intencionalidade da união entre a Igreja e o poder político, quando, depois de dizer que a nobreza deverá agir "em união com os bispos", repete a mesma idéia com outras palavras: "[...] designação de comum acordo". . $^{\circ}$

Na seqüência retórica do cânone 75 , depois da admoestação e a declaração da doutrina, vem a sentença para quem não obedecer o prescrito e os padres do IV Concílio a consideram de tal importância que a repetem por três vezes:

"Ouvi nossa sentença: qualquer de nós que violar o juramento que fez em favor da prosperidade da pátria e do povo dos godos e da conservação da vida dos reis, ou tentar dar morte ao rei, ou debilitar o poder do reino, ou [...], seja anátema [...] e seja excluido de qualquer reunião dos cristãos [...]. E. tornamos a repetir isto por segunda vez, dizendo: de agora em diante qualquer de nós que [...] seja condenado no juizo de Deus. $\mathbf{E}$ ainda proclamamos o mesmo pela terceira vez: de agora em diante qualquer um de nós que [...] seja anátema e estranho à comunhão dos cristãos e não tenha parte com os justos mas com o diabo e com ele seja condenado às penas eternas [...] ${ }^{41}$

Ao ler esta reiteração da sentença, podemos perceber a gravidade do momento histórico e, ao mesmo tempo, o interesse da Igreja na pacífica consolidação do Reino.

38 CONCHUIOS VISIGÓTICOS E HISPANO-ROMANOS. op. cit.: p. 217.

39 idem, p. 218.

40 idem, p. 218.

41 idem, p. 218-19. 
Se o IV Concílio de Toledo se preocupa com a fidelidade devida ao rei, também explicita as obrigações deste para com os súditos. É o caminho de ida e de volta. A segunda parte deste cânone 75, dirigindo-se ao rei, diz assim: " $E$ a ti, nosso rei atual, e aos futuros reis dos tempos vindouros, pedimos que governeis os povos, que vos foram confiados por Deus, com justiça e piedade..$^{42} \mathrm{E}$, descendo aos detalhes, limita o poder régio e pede que respeitem as leis e não governem despóticamente. Quando se tratar do confisco dos bens, ou pena capital, o rei não poderá ser o juíz único. O juízo deverá ser público, guardando a mansidão sem irritação, para que a autoridade se fundamente mais na indulgência do que na severidade.

\section{Conclusão}

É fácil constatar, após a leitura das obras de Isidoro e das Atas Conciliares, como a Igreja intervem na politica, como se plasma em normativa, em leis a serem cumpridas por todos, o pensamento político de Isidoro, o mentor deste IV Concílio. Sob sua égide, a obra legislativa desta Assembléia, animada e dirigida por ele, seria a plasmação constitucional da teoria política isidoriana.

42 idem, p. 220. 